\title{
Conhecimento científico e conhecimento escolar: as dificuldades docentes na transposição didática
}

Scientific and school knowledge: the teaching difficulties in the didactic transposition

\author{
Helena Maria Salla'; Ana Maria de Andrade Caldeira"
}

\section{RESUMO}

A compreensão dos aspectos epitemológicos da produção científica e tecnológica, atreladas a capacidade de compreender as relações existentes entre a Ciência, a Tecnologia e a Sociedade, se apresentam como demandas de uma educação científica que busque a formação de alunos aptos ao exercício pleno de sua cidadania. Nesse sentido, o importante processo de transposição didática do conhecimento científico em conhecimento escolar, inerente à sua prática docente, foi nosso objeto de estudo. Também procuramos elucidar quais as principais adaptações que são feitas em caráter didático e compreender como esse professor enxerga as relações científicas e tecnológicas na sociedade e qual o enfoque dado ao ensino de ciências e biologia nesse sentido. Através de entrevistas com sete professores e, utilizando a metodologia de análise do conteúdo, foi possível verificar que alguns fatores como o interesse do aluno pelo aprendizado e a valorização docente afetam diretamente em sua motivação, além de uma urgente revisão nos objetivos da educação CTS e nos conteúdos apresentados pelo currículo escolar. Esses e outros aspectos devem ser incluídos na formação incial desse professor que deverá ser capaz de promover a transposição de conteúdos, considerados complexos, à realidade e capacidade de compreensão do aluno.

Palavras-chave: Transposição didática. Educação científica. Ensino. 


\section{ABSTRACT}

Understanding the epitemological aspects of scientific and technological production, linked to the ability to understand the relationships between science, technology and society, are presented as demands of a science education that seeks the formation of students able to fully exercise their citizenship. In this sense, the important process of didactic transposition of scientific knowledge into school knowledge, inherent to their teaching practice, was our object of study. We also seek to clarify the main adaptations that are made on a didactic basis and to understand how this teacher sees the scientific and technological relationships in society and what is the focus given to science and biology teaching in this sense. Through interviews with seven teachers and, using the content analysis methodology, it was possible to verify that some factors such as student interest in learning and teacher appreciation directly affect their motivation, in addition to an urgent review of the objectives of STS education and the contents presented by the school curriculum. These and others aspects should be included in the initial formation of this teacher who should be able to promote the transposition of content, considered complex, to the reality and comprehension capacity of the student.

Keywords: Didatic transposition. Science Education. Teaching.

\section{INTRODUÇÃO}

A educação científica se dá através da compreensão dos métodos de produção da ciência, o aprendizado dos dogmas atuais, a compreensão da natureza do conhecimento científico e outros saberes mais específicos que podem resultar em, o aluno conseguir interpretar os fenômenos naturais que acontecem em seu dia a dia, e compreender a influência dessa atividade científica nos diferentes setores da atual sociedade. 
Para Santos (2007), é possível historicamente identificar os perfis de formação científica no contexto brasileiro, considerando que inicialmente a proposta era formar futuros cientistas, que pudessem pensar de maneira objetiva e posteriormente e com o agravamento de problemas ambientais e o progressso científico, começaram a ser inseridas propostas preocupadas em formar "educadores em ciência por uma educação científica que levasse em conta os aspectos sociais relacionados ao modelo de desenvolvimento científico e tecnológico" (SANTOS, 2007, p. 477).

Dessa maneira "torna-se importante discutir os diferentes significados e funções que se têm atribuído à educação científica com o intuito de levantar referenciais para estudos na área de currículo, filosofia e política educacional que visem analisar o papel da educação científica na formação do cidadão" (SANTOS, 2007, p.475) e assim, delimitar como a educação científica pautada no letramento científico do aluno em Ciência e Tecnologia irá efetivamente se transformar em práticas formativas que propiciem o exercício pleno da cidadania.

A capacidade de compreender as relações entre a Ciência, a Tecnologia e a Sociedade se torna uma habilidade que poderá ser desenvolvida a partir da compreensão de aspectos epistemológicos da produção científica, e em nível escolar, se torna uma habilidade a ser desenvolvida nas disciplinas que relacionam a Ciência e a Tecnologia, como é o caso de ciências e biologia, como matérias curriculares ao ensino fundamental e médio, respectivamente.

É importante ressaltar que o contato com os fenômenos científicos não ocorrem apenas na escola, pelo contrário, essa criança é estimulada por anos por atividades científicas antes de começar a compreender que se tratavam de conhecimentos já explicados por teorias da ciência. O conhecimento prévio de determinado assunto nada mais é do que o início da interpretação científica sobre aquele assunto, já que a ciência, propriamente dita poderá ser definida como um conjunto de inferências sobre a observação dos fenômenos naturais.

Assim, o conhecimento científico pode ser entendido como todo conhecimento gerado a partir da ciência, produzido pela atividade científica, ou ainda, todo conhecimento que resulta da interpretação de um fenômeno, ou da observação da 
natureza. Este conhecimento acumulasse ao longo da história da humanidade, e tão antiga quanto a produção desse conhecimento, é a necessidade de ensinar a gerações futuras os conteúdos científicos acumulados nesse processo, sendo o ensino, "certamente um ato tão antigo quanto as mais antigas civilizações" (CHEVALLARD, 2013, p.8).

Nesse processo de ensino, o conteúdo científico que será ensinado é o nosso objeto de estudo, na forma de conhecimento, já que "todo projeto social de ensino e aprendizagem é constituído dialeticamente, com a identificação e designação do conteúdo do saber (conhecimento) como conteúdo a ser ensinado" (CHEVALLARD, 1991, p.45, tradução nossa).

Dentro da área de pesquisas em educação, a Didática, "investiga os fundamentos, condições e modos de realização da instrução e do ensino" (LIBÂNEO, 2013, p.25), pesquisando processos de ensino e aprendizagem. Também é sua função, como área de investigação docente "converter obejtivos sociopolíticos e pedagógicos em objetivos de ensino, selecionar conteúdos e métodos em função desses objetivos, estabelecer os vínculos entre ensino e aprendizagem, tendo em vista o desenvolvimento das capacidades mentais do aluno" (LIBÂNEO, 2013, p.25).

Dessa maneira, o professor que domina os conhecimentos da didática, como área de investigação, conseguirá realizar a "mediação entre as bases téorico-científicas da educação escolar e a prática docente" (LIBÂNEO, 2013, p.27), colaborando com o processo de ensino pois "ela opera como que uma ponte entre "o quê" e o "como" do processo pedagógico escolar" (LIBÂNEO, 2013, p.27)

Considerando que nosso trabalho situa-se nas disciplinas de Ciências e Biologia, a didática dessas áreas em específico "interessa-se pelos processos de transmissão e apropriação dos saberes científicos, recorrendo necessariamente às abordagens epistemológicas e históricas dos conteúdos científicos e dos objetos sociais" (CARVALHO; GIL-PÉREZ, 2011, p.41).

O saber científico e o saber escolar se relacionam como objeto e objetivo da prática docente, já que este saber científico, que é escolhido como um saber a ensinar "passa por um conjunto de transformações adaptativas que o tornarão adequado para ocupar 
um lugar entre os objetos de ensino" (CHEVALLARD, 1991, p.45, tradução nossa). Esse trabalho de transformação do conjunto dos saberes do conhecimento científico a objetos de saber a ensinar é chamado de transposição didática.

A transposição didática pode ser entendida "como um processo "inerente a toda integração de um conceito ao texto do saber escolar"'" (ALTOLFI; DEVELAY, 2011, p.47) e surge como demanda emergente dos estudos no campo da didática (ASTOLFl; DEVELAY, 2011).

Segundo Chevallard (2013), muitas pesquisas são realizadas na tentativa de construir uma análise profunda sobre os processos de ensino e aprendizagem, levando em consideração os atores envolvidos nesse processo: a relação professor e aluno. Dessa maneira, para o autor, esses esforços "se mostraram vãos" (CHEVALLARD, 2013, p.6), já que o conhecimento, que também faz parte dessa relação de ensino aprendizagem é ignorado, é semelhante a "tentar explicar a relação entre o pianista e sua audiência, ou o garçom e seus clientes, ignorando a música ou a comida!" (CHEVALLARD, 2013, p.6).

A problemática central apresentada pelo autor (CHEVALLARD, 2013) é que o conjunto de pessoas que compõem a noosfera (para Chevallard [1991] pode ser entendida como o local onde ocorrerá o encontro daqueles que pensam o funcionamento didático), evitam a discussão sobre a inclusão ou não inclusão do conhecimento dentro da relação didática. “Porque elas espontaneamente ignoram o conhecimento e sua própria relação pessoal com conhecimento, e se concentram apenas, nem tanto na relação que o aluno tem com ele, mas na sua relação com a relação que o aluno possui com 0 conhecimento?" (CHEVALLARD, 2013, p.6)

Assim desenvolvem-se pesquisas que buscam aprofundar o estudo do conhecimento, na área da epitesmologia da ciência, procurando compreender quais serão os saberes a serem ensinados para a nova geração e como ocorre a escolha desses saberes já que "Os saberes a ensinar constituem pois, a herança que uma geração pretende passar à geração seguinte, ou seja o capital cultural que os pais desejam transmitir aos seus filhos" (CARVALHO; GIL-PÉREZ, 2011, p.42).

O trabalho de realizar a transposição didática dos objetos de ensino que serão ensinados se configura como um problema didático que é apresentado ao professor 
diariamente. Munido de recursos didáticos, materiais e, normalmente, um currículo que já vem delimitando os objetivos e objetos de sua prática docente, cabe a esses professor, buscar realizar essa difícil tarefa no contexto escolar.

\subsection{0bjetivos da pesquisa}

Dessa maneira, o objetivo deste trabalho é compreender quais dificuldades são encontradas pelos professores ao realizar transposição didática do conhecimento científico em conhecimento escolar. Também buscamos:

a)elucidar quais as principais adaptações que são feitas em caráter didático;

b)verificar se a linguagem e ou conhecimento prévio dos alunos potencializa esse processo realizado pelos professores. Buscamos ainda, compreender como esse professor enxerga as relações científicas e tecnológicas na sociedade e qual o enfoque dado ao ensino de ciências e biologia nesse sentido.

\section{METODOLOGIA DA PESQUISA}

Sabemos que diversos fatores podem influenciar as práticas de ensino e muitas pesquisas vem sendo realizadas no sentido de investigar esses fatores, sejam eles inerentes a estrutura escolar, a formação docente inicial ou continuada, ou outros fatores do contexto escolar. No entanto, nosso objeto de pesquisa situa-se em investigar, com o foco didático, quais as possíveis dificuldades apresentadas pelos professores na sala de aula dentro desse processo já mencionado como transposição didática, atrelada a prática de ensino.

Acreditamos que a transposição didática que deverá ocorrer para a transformação do conhecimento científico, produto do avanço da Ciência e da Tecnologia, para conhecimento escolar, na forma de saberes que serão ensinado aos alunos se configura como um problema de pesquisa, no qual buscamos compreender quais são, em caráter didático, as principais adaptações realizadas pelo professor. Assim, também 
é inerente ao processo de ensino, compreender qual o enfoque dado a estas relações no Ensino de Ciências e Biologia.

Buscando responder as problemáticas apresentadas, a partir da metodologia de análise de conteúdo (BARDIN, 2009), entrevistamos sete professores de ciências e biologia, que atualmente lecionam na região administrativa da direitoria de ensino de Bauru - SP.

A metodologia escolhida possibilita uma interpretação ampla das entrevistas a partir do estabelecimento de categorias de análise já que é "um tratamento da informação contida nas mensagens" (BARDIN, 2009, p.37) e "qualquer veículo de significados de um emissor para um receptor controlado ou não por este, deveria poder ser escrito, decifrado pelas técnicas de análise de conteúdo"(BARDIN, 2009, p.34).

A metodologia de análise de conteúdo poderá ser definida como "um conjunto de técnicas de análise das comunicações visando obter por procedimentos sistemáticos e objectivos de descrição do conteúdo das mensagens indicadores (quantitativos ou não) que permitam a inferência de conhecimentos relativos às condições de produção/recepção/variáveis inferidas destas mensagens" (BARDIN, 2009, p.44).

\subsection{Perfil dos entrevistados}

A fim de compreender melhor a realidade dos professores entrevistados analisaremos abaixo algumas característica relativas a sua prática docente: qual(is) os anos que leciona, na rede pública ou particular, o tempo que já leciona e se exerce atividade em mais de uma escola.

Em relação à série, 57\% dos professores entrevistados estão lecionando para o $6^{\circ}$ ano, $1^{\text {a }}, 2^{\text {a }}$ e $3^{\mathrm{a}}$ série do ensino médio. $86 \%$ para os $7^{\circ}$ e $8^{\circ}$ ano do ensino fundamental e apenas o $9^{\circ}$ ano é representado por $100 \%$ dos professores. 
Gráfico 1 - Perfil dos professores de acordo com as séries que atualmente estão dando aula

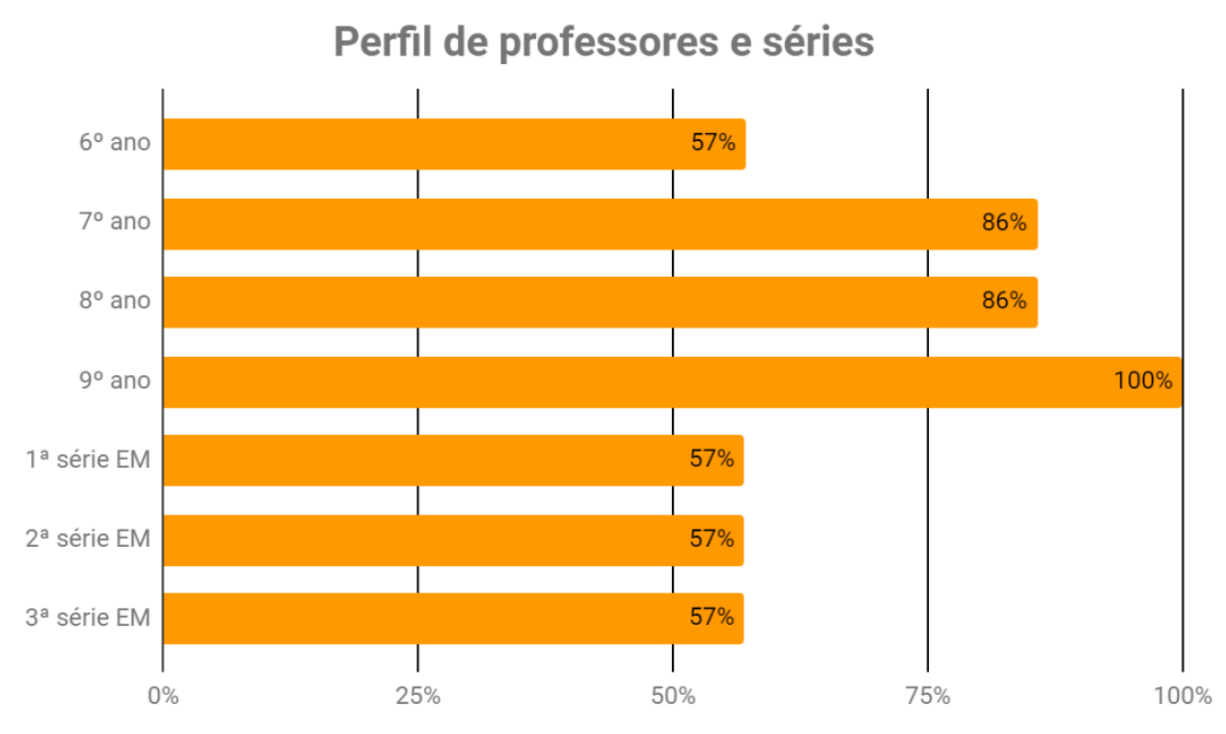

Fonte: autoria própria

Já em relação a escola, a grande maioria dos professores leciona exclusivamente na rede pública estadual de ensino, 71\%, e 29\% na rede particular de ensino. Para efeito de identificação e possíveis interpretações nas respostas das entrevistas, lecionam em escolas particulares, os professores identificados a seguir como 2 e 5.

Gráfico 2 - Perfil dos professores em relação à escola que lecionam: pública estadual ou particular

\section{Perfil de professores e escolas}

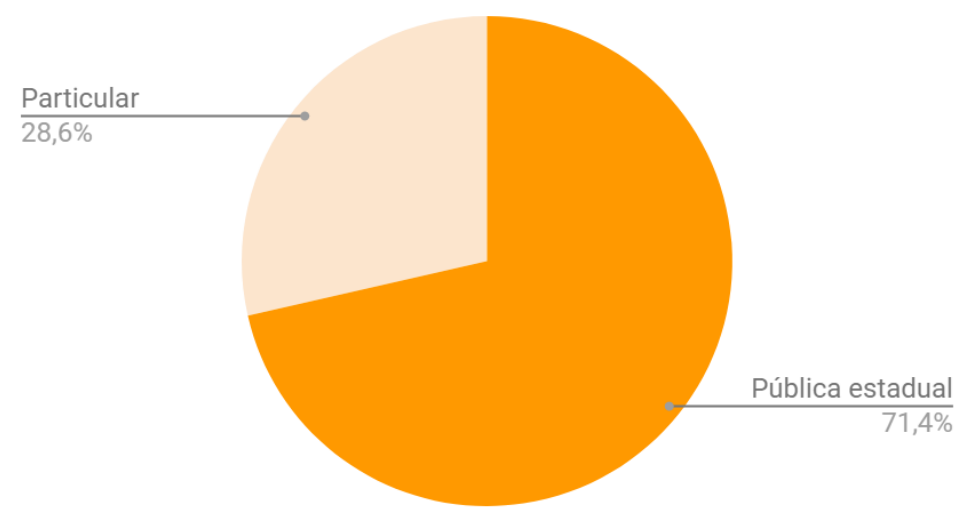

Fonte: autor 
Em relação ao tempo de prática docente, temos a tabela a seguir:

Tabela 1 - Tempo, em anos, que cada professor entrevistado já dá aulas

\begin{tabular}{l|l|l|l|l|l|l|l}
\hline Professor & 1 & 2 & 3 & 4 & 5 & 6 & 7 \\
\hline Tempo de docência (em anos) & 8 & 4 & 11 & 16 & 4 & 5 & 6 \\
\hline
\end{tabular}

A média do tempo de docência dos professores entrevistados é de 7,7 anos. Consideramos este um número relevante pois se tratam de professores com um tempo de experiência como docentes que já é maior do que o tempo médio em cursos de formação inicial em licenciaturas, e este professor já pode apresentar evoluções e adaptações em sua dinâmica de aula.

\section{ANÁLISE DE DADOS}

Organizamos então os processos metodológicos de desenvolvimento da pesquisa, conforme os pólos cronológicos: "pré análise, exploração do material e tratamento dos resultados, inferência e interpretação" (BARDIN, 2009, p.121). Estabelecemos dessa maneira, a partir da pré-análise, o agrupamento das afirmações em 3 categorias, são elas: Dificuldades Gerais, Educação CTS (Ciência,Tecnologia e Sociedade) e Formação Docente.

Para fins de identificação, nos referiremos a partir de agora ao professores através dos numerais de 1 (um) a 7 (sete).

\subsection{As principais dificuldades de âmbito geral}

Para compreender as principais dificuldades apresentadas pelos professores no processo de ensino e consequentemente, transposição didática e quais são as principais adaptações realizadas nesse sentido, é primário colocarmos que "os processos educativos são suficientemente complexos para que não seja fácil reconhecer todos os 
fatores que os definem" (ZABALA, 1998, p. 16) e assim, essa dificuldade poderá ser superada através do desafio de reflexão em cima de sua prática docente.

Refletir sobre a prática, porém, não seria real, se esses fatores forem isolados ou ignorados no processo de reflexão, já que a "prática obedece a múltiplos determinantes, tem sua justificação em parâmetros institucionais, organizativos, tradições metodológicas, possibilidades reais dos professores, dos meios e condições físicas existentes, etc" (ZABALA, 1998, p.16).

Dessa maneira, essa categoria atende aos desafios que aparecem de maneira geral na prática docente e que não são específicos a um instrumento ou obstáculo didático, mas que influenciam a prática pois se apresentam como dificuldades gerais para o professor, e assim, consequentemente, ao processo de ensino. Agrupamos as afirmações dos professores nessa categoria em 2 sub-categorias: interesse e valorização docente.

O interesse do aluno pelo aprendizado e pela escola é um fator de dificuldade apresentada pelos professores. De maneira geral, o aluno é desmotivado e não se interessa pelos resultados que a escola pode proporcionar, como aponta a tabela 2.

Tabela 2 - Trechos da entrevista dos professores sobre as dificuldades gerais relacionadas ao interesse dos alunos

\begin{tabular}{l|l}
\hline \multicolumn{1}{l}{ INTERESSE } & $\begin{array}{l}\text { Tem muitos alunos hoje em dia que não querem aprender, então a } \\
\text { dificuldade maior estão neles... a maior dificuldade é você ensinar alguém } \\
\text { que não quer aprender, é a parte mais difícil de ser professor. }\end{array}$ \\
\hline $\mathbf{5}$ & Principalmente a questão desmotivação por parte dos alunos. \\
\hline $\mathbf{6}$ & $\begin{array}{l}\text { O interesse deles também desmotiva, quando eles não estão interessados, } \\
\text { você tá lá falando e vê que tá falando sozinha, que ninguém tá escutando, } \\
\text { ninguém tá entendendo, ninguém tá participando, isso desmotiva. }\end{array}$ \\
\hline
\end{tabular}

Como aponta o professor $n^{\circ} 1$, ensinar alunos que não tem interesse em aprender é sua maior dificuldade, já que trata-se de um processo cognitivo opcional. Esse aluno está presente na escola, fisicamente, mas não está interessado em como essa permanência pode resultar em aprendizado e consequentemente, em algo siginificativo 
para sua vida. O professor $n^{\circ} 5$ confirma essa perspectiva colocando como uma de suas principais dificuldades a motivação do aluno.

Essa falta de interesse afeta diretamente a motivação docente, como aponta o professor $n^{\circ} 6$, que afirma que por vezes não existe interação e/ou aprendizado por parte dos alunos. Dessa maneira, podemos considerar relevante entender como ocorre a valorização docente, já que o aprendizado do aluno e seu interesse em aprender e se apropriar do que foi preparado por aquele professor se torna uma forma de valorização e motivação docente.

Tabela 3 - Trechos da entrevista dos professores sobre as dificuldades gerais relacionadas à valorização docente

\begin{tabular}{l|l}
\hline \multicolumn{2}{l}{ VALORIZAÇÃO DOCENTE } \\
\hline $\mathbf{2}$ & $\begin{array}{l}\text { Na escola particular, é os alunos ver o professor como um empregado deles. } \\
\text { Parece que estamos fazendo um favor para eles porque eles estão pagando o } \\
\text { salário da gente }\end{array}$ \\
\hline $\mathbf{6}$ & $\begin{array}{l}\text { Sempre dei sorte, considero uma sorte, de ficar apenas em uma escola e mesmo } \\
\text { tendo } 40 \text { aulas semanais dividida em 20/20 em cada cargo eu fui sortuda de } \\
\text { estar nos dois (cargos) na mesma escola. O governo não valoriza o professor. }\end{array}$ \\
\hline & $\begin{array}{l}\text { Sem falar da desvalorização, acho que cada ano que passa o professor é mais } \\
\text { desvalorizado. Tem aluno que chega assim, no sexto ano e fala "minha mãe } \\
\text { falou que você não manda em mim" }\end{array}$ \\
\hline
\end{tabular}

Dois panoramas são bem distintos acerca da valorização do professor da rede pública e privada nesse sentido. O professor 2 , aponta que na rede privada, o aluno pode entender que o serviço pelo qual está remunerando a escola e consequentemente o professor, faz com que este esteja a seu serviço, já que existem relações com o capital e na rede pública, a valorização dos estados e municipios, aparece na fala do professor 4 , que aponta a questão da carga horária.

Já o professor $n^{\circ} 6$, aponta a difícil relação que se estabelece entre a instituições de formação humana: escola e família. Dessa maneira, para tentar compreender os motivos pelo qual esses alunos não se interessam pelo aprendizado em ciências e não valorizam o papel do professor é necessário questionar o papel da escola em nossa 
sociedade atualmente e como a motivação por parte dos atores desses processos educativos ocorre.

Entretanto, é necessário aqui retomar o que já foi colocado na Introdução por Chevallard (2013) acerca da exclusão do conhecimento na análise "dos atores" dentro do processo educativo: professor e aluno, não se considerando muitas vezes o conteúdo científico como parte dessa relação de ensino e aprendizagem.

O conhecimento se apresenta de forma significativa para o aprendizado do aluno? Ele é pauta de discussões entre os professores e nas reuniões com a direção da escola e/ou os pais? O aluno enxerga a aplicação social para obtenção daquele saber?

\subsection{Educação CTS}

Como levantado anteriormente, o aluno não quer aprender e não se interessa pela aula de ciências e biologia, entretanto muitos professores apontam que a contextualização é fundamental para situar o conteúdo para o aluno e gerar interesse.

Devem existir incontáveis variáveis de análise para esse fenômeno de interesse dos alunos, algumas já analisadas aqui, mas é um dos desafios para o professor e para a transposição didática superar esse (des)interesse e auxiliar o aluno a visualizar a utilidade daquele aprendizado, motivando-o. Enxergamos assim, que a inclusão de aspectos de Ciência, Tecnologia e Sociedade (CTS) no ensino pode colaborar em algumas instâncias com essas problemáticas apresentadas.

Para compreender o conteúdo que está sendo ensinado e também gerar envolvimento, os professores comentam que a contextualização faz esse importante papel, de situar o conteúdo para o aluno.

Como aponta o professor $n^{\circ} 6$, o aluno pode questionar a usualidade prática daquele saber, em entender o motivo daquele aprendizado para sua vida. Para os professores 1 , 3 e 7, a contextualização irá exercer esse papel, de relacionar com a realidade do aluno e assim gerar envolvimento, já que cada aluno entende de maneira diferente o conteúdo, como afirma o professor $n^{\circ} 7$. 
Tabela 4 - Trechos da entrevista dos professores sobre seleção de conteúdos, especificamente a contextualização

\begin{tabular}{l|l}
\hline \multicolumn{2}{l}{ CONTEXTUALIZAÇÃo } \\
\hline $\mathbf{1}$ & $\begin{array}{l}\text { O importante é você mostrar a importancia daquilo... sempre trazer muito } \\
\text { para a realidade deles. }\end{array}$ \\
\hline $\mathbf{3}$ & $\begin{array}{l}\text { Comparando o meio em que os alunos vivem com o que é explicado em } \\
\text { aula. }\end{array}$ \\
\hline $\mathbf{6}$ & As vezes eles perguntam "pra que eu vou usar isso professora?" \\
\hline $\mathbf{7}$ & $\begin{array}{l}\text { O aluno possui uma percepção diferente da sua aula, então você tem que } \\
\text { aproximar o máximo daquilo que você é, da realidade do aluno, da } \\
\text { maneira como ele entende. }\end{array}$ \\
\hline
\end{tabular}

Dessa maneira, podemos avaliar que a contextualização do conteúdo a ser ensinado, se torna em um mundo globalizado, uma demanda quase que obrigatória de adaptação dos conteúdos pelos professores, que não serão mais introduzidos apenas de maneira tradicional mas selecionados e contextualizados dentro de uma sequência didática. "É precisamente nesta questão da seleção dos conteúdos, dos saberes a serem ensinados que se enraíza a noção didáctica" (CARVALHO; GIL PÉREZ, 2011, p.42).

O espaço escolar configura-se como um dos principais cenários onde o conhecimento científico será apresentado ao aluno em formação e por isso, precisa ser adaptado. “A escola constitui, pois, o espaço privilegiado para a transmissão, por um lado, da cultura universal, e por outro, dos saberes justificados por um determinado contexto socioeconomico e politico" (CARVALHO; GIL-PÉREZ, 2011, p.42).

Estes saberes justificados, representam os saberes que serão ensinados ao final do processo de transposição didática. “O saber tal-como-é-ensinado, o saber ensinado, é necessariamente distinto do saber-inicialmente-designado-como-o-saber-que-deve-serensinado, o saber a ensinar" (CHEVALLARD, 1991, p.17, tradução nossa).

Dessa maneira, tratando especificamente da relação social desses saberes, questionamos os professores sobre a concepção em relação a tópicos de Ciência, Tecnologia e Sociedade no ensino e alguns professores levantaram pontos relevantes sobre o que significa essa inclusão e como isso pode auxiliar o aprendizado dos alunos. 
Tabela 5 - Trechos da entrevista dos professores sobre CTS, especificamente a concepção de alguns professores sobre o assunto

\begin{tabular}{l|l}
\hline \multicolumn{2}{l}{ CONCEPÇÃO } \\
\hline $\mathbf{1}$ & $\begin{array}{l}\text { Uma coisa que eu trabalho muito é essa ideia de relacionar para o dia-a-dia. A } \\
\text { importância da ciência, principalmente a tecnologia hoje em dia. }\end{array}$ \\
\hline $\mathbf{2}$ & $\begin{array}{l}\text { Eu tento fazer sempre que possível para poder mostrar mesmo uma aplicação } \\
\text { daquele conteúdo. Fica difícil de ensinar sem ter uma contextualização. }\end{array}$ \\
\hline $\mathbf{3}$ & São feitas correlações com a realidade do cotidiano do aluno. \\
\hline $\mathbf{5}$ & $\begin{array}{l}\text { Conforme a idade eu procuro sim porque eu tive uma formação na Unesp e ela foi } \\
\text { moderna e não foi só uma biologia conteudista, ela foi entender a aplicação mesmo } \\
\text { da biologia. }\end{array}$ \\
\hline $\mathbf{6}$ & $\begin{array}{l}\text { Não tive esse tema na faculdade, então acredito que faço indiretamente. Procuro } \\
\text { contextualizar e inserir interdisciplinaridade em minhas aulas. }\end{array}$ \\
\hline & $\begin{array}{l}\text { A nova proposta da BNCC fala muito sobre ciência e tecnologia. Hoje em dia não } \\
\text { tem como ignorar tecnologia dentro da sala de aula, porque se a ignorar a sala, a } \\
\text { aula vai ficar chata. }\end{array}$ \\
\hline
\end{tabular}

Relacionando ainda com as últimas falas analisadas na contextualização, quando questionados sobre a concepção CTS e a inclusão em suas aulas, os professores $n^{\circ} 2$ e $n^{\circ} 4$, abordaram a questão da aplicação de conteúdo, que se contextualizado facilita o aprendizado, e como aponta o $n^{\circ} 4$ ainda existe uma interferência em relação a idade.

Já os professores $n^{\circ} 1$ e $n^{\circ} 6$ levantam a questão da tecnologia, em utilização na sociedade atual e como a dinamicidade dos conteúdos que acontece em função do avanço da tecnologia interfere na sala de aula e, consequentemente, na prática didática.

O professor n 1 afirma "a importância da tecnologia hoje em dia" e essa concepção já identificada por outros autores como Auler (2011) representa uma visão que o desenvolvimento científico e tecnológico é de certa maneira, sempre positivo, já que foi atribuído a ele um caráter de salvador. "Uma segunda construção histórica, transformada em mito, afirma que, em algum momento do presente ou futuro, CT resolverão os problemas, hoje, existentes, conduzindo a humanidade ao bem estar social" (AULER, 2011, p.76).

Por isso, a inclusão de aspectos CTS na transposição didática também se faz relevante para entender os benefícios e os eventuais riscos da produção científica e tecnológica e 
como esta é influenciada diretamente por outros setores sociais. A relação dessa produção com o dia-a-dia também é apontada pelos professores 1 e 6 como importante para a compreensão e o interesse do aluno. Essa relação "é permanentemente construída pelos meios de comunicação no dia a dia do cidadão, o que, de certa forma, pode favorecer a percepção de processos que envolvem essa relação" (BERNARDO, VIANNA, SILVA, 2011, p.376).

O professor $n^{\circ} 5$ cita que não teve em sua formação inicial essa temática, e comenta sobre a interdisciplinaridade, que apesar de ser outra relevante alteração das práticas curriculares, não se refere diretamente à compreensão dos processos científicos e tecnológicos e sua aplicação na sociedade e sim, ao relacionamento de interdisciplinas curriculares em práticas coletivas, considerando portanto, um erro conceitual à concepção desse professor sobre CTS. O que é compreensível já que o professor não teve esse assunto mencionado em sua formação inicial.

Além deste erro conceitual acerca da interdisciplinaridade, também é possível identificar na fala do professor $n^{\circ} 6$ um comum erro no relacionamento da tecnologia analisada dentro dos conceitos da área de CTS e da tecnologia na forma de dispositivos móveis aplicados ao ensino, TICS. A concepção de abordar o desenvolvimento científico e tecnológico não é excludente a utilização prática de tecnologias em sala de aula, articuladas com os objetivos de ensino, mas não significam a mesma coisa e a simples utilização de uma ferramenta online de busca não irá gerar reflexão no aluno sobre a produção social dessa tecnologia.

Assim, a relação Ciência, Tecnologia e Sociedade engloba os pontos anteriores acerca da contextualização e das concepções e para compreender melhor sua influência na transposição didática perguntamos aos professores se eles incluem em sua prática e como isso influencia seu aprendizado.

É unânime a opinião por parte dos professores que a inclusão de práticas CTS favorece o aprendizado, pois aproxima da realidade, como aponta o professor $n^{\circ} 2$, e faz mais sentido para o aluno, dinamiza e gera significado, como aponta o professor $n^{\circ} 4$ e assim gera interesse, como aponta o $\mathrm{n}^{\circ} 7$. 
Tabela 6 - Trechos da entrevista dos professores sobre CTS, especificamente o favorecimento do aprendizado

\begin{tabular}{l|l}
\hline \multicolumn{2}{l}{ FAVORECIMENTO DE APRENDIZADO } \\
\hline $\mathbf{1}$ & $\begin{array}{l}\text { Eu trabalho muito essa ideia de relacionar para o dia-a-dia e isso proporciona } \\
\text { para eles uma visão mais palpável do assunto. }\end{array}$ \\
\hline $\mathbf{2}$ & $\begin{array}{l}\text { O que você está ensinando começa a fazer mais sentido para o aluno. } \\
\text { Simplesmente apresentar o tema sem fazer nada dessa correlação fica } \\
\text { complicado de despertar o interesse do aluno. }\end{array}$ \\
\hline $\mathbf{3}$ & $\begin{array}{l}\text { É através desta correlação que os alunos irão melhor entender o conteúdo e } \\
\text { onde estão inseridos. }\end{array}$ \\
\hline $\mathbf{4}$ & $\begin{array}{l}\text { Favorece porque toda vez que você relaciona a prática com o ambiente com algo } \\
\text { que ele convive fica muito mais fácil. Isso torna o aprendizado mais dinâmico e é } \\
\text { aquela aprendizagem significativa né. }\end{array}$ \\
\hline $\mathbf{6}$ & $\begin{array}{l}\text { Acredito que favorece mas faltou isso em minha formação inicial. } \\
\mathbf{7}\end{array}$ \\
\hline
\end{tabular}

Ressaltaremos apenas o cuidado a ser tomado pela fala do professor $n^{\circ} 2$, buscando não atribuir ao ensino de ciências um caráter instrumental, utilitarista, já que a educação em ciências no Brasil não possui esse viés (Auler, 2011). O professor n¹ levanta a capacidade que essa inclusão de práticas CTS gera em tornar "visão mais palpável do assunto" e o professor $n^{\circ} 4$ a contrução de significado. Isso é relevante pois busca-se de maneira geral, "a constituição de níveis mais abstratos de pensamento, e no campo epistemológico, a superação da concepção de que na educação, na escola, há apenas reprodução, apropriação de conhecimentos, da cultura produzida historicamente" (AULER, 2011, p.92).

Por fim, os principais desafios para a implementação levantados anteriormente e as possibilidades de facilitação do processo de transposição dos saberes a serem ensinados, irão demandar "mudança de atitude do professor frente aos desafios impostos pela organização escolar e pelos currículos tradicionais" (BERNARDO, VIANNA, SILVA, 2011, p.377).

Para Bernardo, Vianna e Silva (2011), esses espaços fornecem a possibilidade do desenvolvimento de uma autonomia que é indispensável aos professores que querem 
discutir as relações CTS com seus alunos, essa discussões"podem oferecer condições concretas que auxiliem os participantes a pensarem essa mudança, a partir da conscientização sobre a importância das relações entre ciência, tecnologia e sociedade" (BERNARDO, VIANNA, SILVA, 2011, p.389).

\subsection{Formação docente}

Uma outra importante tarefa do professor ao preparar sua aula é escolher quais serão os direcionamentos teóricos para o conteúdo e dentro dessa categoria foi possível encontrar aspectos relevantes acerca da complexidade e da linguagem, adaptações feitas pelo professor e aspectos relacionados ao aprendizado do aluno.

Ainda sobre o tópico discutido anteriormente, o professor $n^{\circ} 2$ aponta que $\mathrm{o}$ aprendizado poderá ser facilitado se o aluno relacionar o conteúdo com o seu dia-a-dia, porque isso irá ter "mais sentido". Essas adaptações de conteúdo e relações com o cotidiano serão então ferramentas de transposição do saber a ser ensinado pelo professor e outros professores apontam que a complexidade dos conteúdos se torna um desafio nesse sentido, já que o processo de simplificar didáticamente um conteúdo complexo é extramente complexo em sua própria natureza epistemológica.

Essas adaptações aos conteúdos complexos aparecem nas falas dos professores $n^{\circ} 1$, 5 e 7 , sendo que os professores 5 e 7 falam respectivamente sobre, introduzir algo mais simples para posteriormete chegar ao complexo e a compreensão do complexo pelo professor antes de introduzi-lo ao aluno.

Considerando que o saber a ensinar (objeto de ensino) que já é introduzido ao professor pelo currículo é o que está sendo considerado pelos professores como complexo, o processo de simplificar que eles se referem são as eventuais transformações realizadas pelo professor, como problema didático para adaptar, transformando esse saber em saber escolar, a ser ensinado.

Para Chevallard (1991) essa trajetória do saber, objeto de estudo da sua teoria de transposição didática, poderá apresentar problemáticas oriundas de distorções conceituais no objeto ensinado, e por isso é necessário encurtar essa distância que 
separa esses saberes, exercendo o que o autor chama de vigilância epistemológica (CHEVALLARD, 1991).

Tabela 7 - Trechos da entrevista dos professores sobre formação de professores, especificamente a complexidade

\begin{tabular}{l|l}
\hline COMPLEXIDADE & $\begin{array}{l}\text { As dificuldades maiores dos temas são que alguns temas são muito } \\
\text { complexos e é preciso adaptação. }\end{array}$ \\
\hline $\mathbf{1}$ & $\begin{array}{l}\text { Quanto mais o professor busca essas informações e as aplicações no dia a } \\
\text { dia, que faz com que aquele conteúdo tenha mais sentido para o aluno, } \\
\text { acho que facilita o aprendizado. }\end{array}$ \\
\hline $\mathbf{4}$ & $\begin{array}{l}\text { Nada é fragmentado, a gente precisa ensinar as coisas de uma maneira } \\
\text { fragmentada para que ele aprenda, mas as coisas são dinâmicas. }\end{array}$ \\
\hline $\mathbf{5}$ & $\begin{array}{l}\text { Procuro introduzir o conteúdo complexo com algo mais simples, e } \\
\text { posteriormente dou o conteúdo que a apostila traz. Com os exercícios, não } \\
\text { costumo usar os da apostila, e sim, preparar listas menos complexas. }\end{array}$ \\
\hline $\mathbf{7}$ & $\begin{array}{l}\text { As vezes o aluno precisa ver na prática, para dar um significado. } \\
\text { O conteúdo é denso, as vezes precisa buscar outras fontes, fazer um } \\
\text { esforço maior para que você possa entender o conteúdo de maneira que } \\
\text { você consiga com segurança transmitir para o aluno. }\end{array}$ \\
\hline
\end{tabular}

Outro ponto a ser analisado é a fragmentação do conteúdo, que aparece na fala do professor $n^{\circ} 4$, como mecanismo de compreensão para o aluno, que para aprender será ensinado de maneira fragmentada mas a compreensão geral deveria ser dinâmica, completa. O professor $n^{\circ} 6$ aborda ainda questão da visualização prática para compreensão, para gerar um significado do conteúdo.

Se considerarmos que os conteúdos que são colocados para serem aprendidos pelos alunos em ciências e biologia, de maneira relacionada podemos entender que "existem conhecimentos (em sentido amplo: conhecimentos e procedimentos) que definem o ato de ensinar como uma compreensão reflexiva de seus objetivos e a explicação de sua intenção didática" (CHEVALLARD, 1991, p.67).

Assim a concepção apresentada pelo professor $n^{07}$ se torna ultrapassada pois considera que a transmissão do saber do saber a ser ensinado uma transmissão que 
depende do entendimento do conteúdo pelo professor e ignora a noção didática acerca da reflexão sobre a obtenção daquele saber e outros fatores que influenciam.

Dessa maneira, a linguagem é um ponto fundamental de análise pois influencia diretamente o modo como o conteúdo é compreendido pelo professor e pelo aluno na construção de uma aprendizagem signifcativa.

Tabela 8 - Trechos da entrevista dos professores sobre formação de professores, especificamente referentes à linguagem

\begin{tabular}{|c|c|}
\hline \multicolumn{2}{|c|}{ LINGUAGEM } \\
\hline 1 & $\begin{array}{l}\text { É dificil olhar a linguagem, você tem que trazer para o ambiente da sala de } \\
\text { aula, tornar aquilo uma conversa, mas uma conversa que seja em um nível } \\
\text { adequado, eu não posso trabalhar com temas muito científicos. }\end{array}$ \\
\hline 3 & $\begin{array}{l}\text { Na minha aula eu coloco muitos desenhos e peço para eles desenharem } \\
\text { como, por exemplo, o ciclo da água. }\end{array}$ \\
\hline 4 & $\begin{array}{l}\text { No ensino médio é mais fácil de relacionar porque eles já conseguem ir do } \\
\text { concreto para o abstrato. }\end{array}$ \\
\hline 7 & Nem sempre você vai conseguir alcançar o aluno na mesma medida. \\
\hline
\end{tabular}

A linguaguem em Ciências e Biologia não será somente a língua portuguesa escrita mas também a utilização de recursos visuais, como desenhos e esquemas que irão facilitar a compreensão e organização do conteúdo para o aluno, como aponta o professor $n^{03}$ ao incluir desenhos e ciclos nos conteúdos onde essa adaptação é possível.

Já o professor $n^{\circ 1}$ aponta uma dificuldade em encontrar um nível de adaptação da linguagem científica para o ambiente escolar, já que ele aponta a impossibilidade de incluir temas muito científicos. A transposição e adaptação dos conceitos nesse momento se faz importante para introduzir conceitos considerados "muitos científicos" de maneira que o aluno compreenda o processo de evolução da obtenção daqueles conhecimentos.

O professor $n^{\circ} 4$ já levanta um ponto positivo ao aluno do ensino médio que consegue compreender relações concretas e abstratas, nas quais acreditamos ser um processo de 
abstração fundamental para trabalhar assuntos não visíveis a olho nú, como processos microscópicos e relações ecológicas, por exemplo.

Por fim, separamos duas falas sobre o aprendizado dos saberes pelos alunos apresentadas pelos professores 2 e 4 .

Tabela 9 - Trechos da entrevista dos professores sobre o aprendizado dos alunos

\begin{tabular}{|c|c|}
\hline \multicolumn{2}{|c|}{ APRENDIZADO } \\
\hline 2 & $\begin{array}{l}\text { A maior dificuldade mesmo, principalmente no ensino da Biologia, são } \\
\text { aqueles temas que você não consegue muito estimular o raciocínio do } \\
\text { aluno, são temas que o aluno meio que tem que decorar. }\end{array}$ \\
\hline 4 & $\begin{array}{l}\text { A maior dificuldade é realmente não atrasar o currículo e superar as } \\
\text { defasagens. Você tem que mudar a todo momento, a aprendizagem } \\
\text { precisa ser significativa, se não ela só se torna conteudista. }\end{array}$ \\
\hline
\end{tabular}

O professor $n^{\circ} 2$ comenta sobre o estímulo ao raciocínio do aluno, onde em determinados assuntos não é possível desenvolver essa capacidade e assim, o aluno tem que decorar o conceito. No entanto, o professor 4 atribui ao professor essa responsabilidade de não deixar o aprendizado "conteudista".

Segundo Carvalho e Gil-Pérez (2011) conhecer a matéria que será ensinada é uma necessidade consensual entre os professores e apesar de parecer supérfluo, do ponto de vista do conhecimento, é um importante ponto de questionamento e do ponto de vista didático: fundamental.

Nesse sentido, conhecer a matéria não é significado direto de conseguir realizar que contemple as dificuldades pelos professores, mas também é um fator importante, que poderá colaborar na atribuição da linguagem que será utilizada e influencia assim, diretamente, o aprendizado do aluno.

\section{CONCLUSÕES}

A valorização docente, que também está atrelada a muitos fatores de dificuldades gerais apresentadas pelos professores, articula alguns dos pontos apresentados como a motivação do professor em desenvolver novas práticas e importantes pontos de sua 
formação continuada. Essa valorização também está ligada ao tempo disponível que esse professor tem para estudar e se atualizar dentro da profissão.

Atrelada a valorização e a atualização do docente os dois fatores se configuram como dificuldades a transposição didática a medida que o ambiente de trabalho não colabora para a contrução de uma prática social de ensino com qualidade, o professor não é valorizado de diferentes maneiras e o aluno não o motiva pois não se interessa no que esse professor pode colaborar para sua formação.

A partir das falas dos professores, foi possível verificar que, independente do cenário público ou privado, o ensino gera pouco interesse no aluno, que não enxerga possibilidades na aplicação social daqueles aprendizados, na obtenção daqueles saberes. Essa falta de interesse do aluno também contribui para a desmotivação do professor e das novas práticas que poderiam ser propostas nesse sentido.

Uma alternativa ao ensino de Ciências e Biologia, se apresenta com a articulação entre os conteúdos curriculares e a proposta de um ensino CTS, considerando o desenvolvimento científico e tecnólogico de maneira crítica, contextualizada e discutindo a articulação com a sociedade.

Dessa maneira, uma formação que capacite o professor a realizar essas relações e incluir em sua prática aspectos de educação CTS é fundamental para que os objetivos da educação científica sejam contemplados, e esses momentos de formação aparecem nas respostas dos professores.

Acerca da concepção dos professores sobre a inclusão de aspectos de CTS verificamos que não se trata de uma simples contextualização dos conceitos, já que isso se torna consensual e é colocado como um facilitador de ensino. É urgente a revisão sobre as definições e objetivos dessas práticas atreladas a formação dos professores em nível inicial e continuada, já que alguns erros conceituais foram identificados.

É importante que os professores consigam identificar os principais objetivos da educação CTS e dominar as ferramentas necessárias para executá-la, reforçando a necessidade de debater esses cenários junto aos estudantes, facilitando assim a compreensão da natureza do conhecimento científico. 
Essas demandas, devem ser incluídas na formação inicial desse professor, que deverá ser capaz de promover a transposição de conteúdos, considerados complexos, à realidade e capacidade de compreensão do aluno. O aluno deverá ser estimulado por esse professor a raciocinar e não apenas decorar conteúdos científicos, e compreender os processos de produção científica e tecnológica é primordial para possibilitar que esses objetivos de aprendizagem sejam contemplados.

A delimitação de um currículo que potencialize essa comprenssão (tomada de decisões, discussões sociais, influências do campo da ciência e tecnologia) também poderá auxiliar esse professor mas os objetivos não serão suficientemente atingidos caso esse profissional não tenha os recursos didáticos e o conhecimento específico dessa produção, ou ainda, não enxergue a necessidade e os benefícios que essas práticas podem gerar ao processo de ensino e a formação dos estudantes.

\section{REFERÊNCIAS}

AULER, D. Novos caminhos para a educação CTS: ampliando a participação. CTS e educação científica: desafios, tendências e resultados de pesquisas. Brasília: Editora Universidade de Brasília, p. 73-97, 2011.

ASTOLFI, J. P.; DEVELAY, M. A didática das ciências. Trad. Magda SS Fonsceca. 2011.

BERNARDO, JR da R.; VIANNA, Deise M.; SILVA, VHD da. A construção de propostas de ensino em Ciência-Tecnologia-Sociedade (CTS) para abordagem de temas sociocientíficos. Editora UNB: Brasília, 2011.

CARVALHO, A. M. P. de; GIL-PÉREZ, D. Formação de professores de ciências: tendências e inovações. $10^{a}$ ed. São Paulo, Cortez, 2011

CHEVALLARD, Y. Sobre a teoria da transposição didática: algumas considerações introdutórias. Revista de educação, clências e Matemática, v. 3, n. 2, 2013.

CHEVALLARD, Y. La transposición didáctica. Del saber sabio al saber enseñado, v. 3, 1991.

LIBÂNEO, J. C. Didática. 2. Ed. São Paulo: Cortez, 2013.

SANTOS, W. L. P. dos. Educação científica na perspectiva de letramento como prática social: funções, princípios e desafios. Revista Brasileira de Educação, v. 36, p. 474-492 2007. 
ZABALA, A. A prática educativa: como ensinar. Porto Alegre: Artmed, 1998. Como trabalhar os conteúdos procedimentais em aula, 2002. 